\title{
Listeria Monocytogenes : A Major Public Health Concern
}

\author{
Angela Revelas \\ Pathological Department of St.Nicolaos Hospital-Crete, Greece.
}

Corresponding Author: Angela Revelas

E mail:

donnoiko@gmail.com

Listeria monocytogenes, an aerobic and facultatively anaerobic gram-positive bacillus, can be readily isolated from soil, dust, fertilizer, sewage, stream water, plants, and processed foods. The organism is also present in the intestinal tract of numerous mammals, birds, fish and crustaceans.

\section{INTRODUCTION}

Listeria monocytogenes (commonly called Listeria) named for Joseph Lister. Listeria monocytogenes, is the bacterium that causes the infection listeriosis. It is a facultative anaerobic bacterium, capable of graving and reproducing inside the host's cells, and is one of the most virulent food-borne pathogens of clinical infections resulting in death. Listeriosis is the leading cause of death among foodborne bacterial pathogens, with fatality rates exceeding even Salmonella and Clostridium botulinum.

Several foods, including corn, chocolate milk, shrimp and rice salad, have been reported as vehicles [1]. More commonly, however, Listeria monocytogenes causes no evident gastrointestinal lesions or symptoms but rather makes its presence known by severe, life-threatening symptoms involving the central nervous system or the unborn fetus of a pregnant woman.

Pregnant women with listeriosis may experience relatively mild flu-like symptoms themselves. Listeria monocytogenes can spread within their bodies and readily cross the placenta to infect the unborn child. Abscesses develop in the liver, lungs and other fetal organs, and frequently the result is spontaneous abortion or stillbirth. If the baby survives birth, it may be seriously ill with meningitis.

Meningitis is also common in adult victims of listeriosis. Most, but not all, serious cases of listeriosis occur in people who are pregnant, elderly, or have some underlying disease that depresses their immune function.

\section{INTERNALINS}

Listeria monocytogenes is taken into host cells by a process of phagocytosis. Some cells, such as macrophages, are professional phagocytic cells with normally engulf bacteria and dying cells, while other epithelial and endothelial cells are non-professional phagocytes. These cells do not normally phagocytize other cells, but they can be induced to do so. Internalin A was first identified as a listerial surface protein that is required for the penetration of Listeria monocytogenes into non-phagocytic cells, such as epithelial cells[2]. A related protein, internalin $\mathrm{B}$, plays a role in invasion of hepatocytes in the liver [2-6].

Internalin A on the surface of listerial cells binds to a surface protein, Ecadherin, on the surface of host epithelial cells. This interaction stimulates the phagocytosis of Listeria monocytogenes cells [7]. 


\section{EPIDEMIOLOGY}

Listeria can be phagocytosed by gastrointestinal cells, and macrophages, it can enter the host without disrupting the integrity of the gastrointestinal tract. Subsequently, Listeria, commandeers the host-cells contractile proteins actin, VASP, and profiling to spread from cell to cell and eventually enter the bloodstream either in monocytes and neutrophils or as free organisms after cell lysis. Listeria's intracellular life cycle may explain the increased incidence of listeriosis, in immunocompromised patients, neonates, and pregnant women. Since Listeria manages to avoid the extracellular environment, immunoglobulins and complement would not be expected to have prominent roles in protecting the host against this pathogen. Patients with AIDS are most likely to contract Listeria infection when their CD4+T-lymphocyte counts fall below 40/cubic millimeter.

Listeria can cause a number of clinical syndromes, including sepsis and focal infections of the bones, joints, eyes, endocardium, spinal cord, peritoneum, and gall bladder. Two syndromes that may result in manifestations that are unique to listeriosis are meningitismeningoencephalitis and granulomatosis infantiseptica.

\section{TEMPERATURE}

Listeriae can survive and grow at low temperatures $\left(4-25^{\circ} \mathrm{C}\right)$, but under these conditions listeriolysin $\mathrm{O}$ production is reduced or abolished. It takes only 2 hours at $37^{\circ} \mathrm{c}$ for listeriolysin $\mathrm{O}$ to return to normal [8-10].

\section{IRON}

Growth in an iron-rich medium enhanced the invasiveness of Listeria monocytogenes for $\mathrm{CaCo}-2$ cells by increasing the expression of internalin genes[11]. Availability of iron also affects expression of the Act A protein[12].

\section{EFFECTS OF PREGNANCY}

The fetus contains traits from the father that are antigenically foreign to the mother, and therefore her immune system should reject the fetus. Although the immunomodulation allows the fetus to survive, it also increases susceptibility to intracellular pathogens, that are normally attacked by the cellular immune system. Listeria monocytogenes, other intracellular pathogens such as Coxiella burnetii, Toxoplasma gondii, and hepatitis E virus may cause severe illness in pregnant women and/or their fetuses[13]. Infants also respond inadequately to listerial infection. Examination of the in vitro immune response to Listeria monocytogenes by one-yearold infants who previously had a severe listerial infection at birth revealed that they produced neither antibodies nor a cell-mediated response to Listeria monocytogenes. Their immune system had no memory of encountering this pathogen previously. The mothers of these infants did respond immunologically to a challenge with Listeria monocytogenes[11].

Some experiments with mice indicated that the immune response was impaired in the fetoplacental unit but in other tissues, such as liver and spleen[14]. Some monocytes and macrophages were observed in the placental region but they were not present at the foci of listerial infection and macrophages were not appropriately activated [15].

Immunochemical staining confirmed that macrophages were not present in the placenta proper nor were the macrophage inflammatory protein or the monocyte chemoattractant protein detectable in the placenta[16]. All of these deficiencies in immune function permit the growth of listeria monocytogenes in the placenta and fetus.

\section{PATIENTS AND LISTERIA}

Immunocompromised individuals are particularly vulnerable to this intracellular pathogen with Listeria infection underlying immonosuppresion [17]. Other groups of individuals at increased risk include those on drugs which reduce gastric acidity, patients with eithosis, hemochromatosis, and chronic renal failure patients with frequent transfusions. Clinical manifestations of invasive listeriosis are usually severe and include abortion, sepsis, and meningoencephalitis. Listeriosis can also manifest as a fibrate gastroenteritis syndrome. In addition to humans, Listeriosis monocytogenes affects many vertebrate species, including birds. Pathogenic Listeria enters the host primarily through the intestine. The liver is thought to be the first target organ after intestinal translocation.

\section{ANTIBIOTIC TREATMENT}

Bacteriostatic drugs, such as chloramphenicol and tetracycline, are associated with high failure rates in patients with listeriosis and therefore cannot be recommended. Ampicillin or penicillin 
has generally been recommended as the treatment of choice. Nonetheless, in immunosuppressed patients, relapses have been reported after two weeks of penicillin therapy. The poor response to bacteriostatic drugs and the slow response to penicillin probably result from listeria's ability to survive and grow within cells. The intracellular concentration of ampicillin or penicillin may not be sufficient for complete sterilization.

Immunosuppression reduces the host's ability to clear infected cells, allowing listeria to survive and spread for prolonged periods in a protected intracellular environment. Antibiotic treatment for three to four weeks is therefore recommended in immunosuppressed patients.

Antibiotics that penetrate cells poorly, such as aminoglycosides, may be synergistic in vitro but are unlikely to prove effective in the living host. Although some experts have recommended adding an aminoglycoside to ampicillin, Listeria continues to grow in cells despite extracellular concentrations of 10 to $20 \mu \mathrm{g}$ of gentamicin per milliliter. Aminoglycosides are therefore unlikely to be effective in the treatment of listeriosis and should certainly be avoided in treating kidney-transplant recipients and other patients with renal dysfunction.

Trimethoprim-Sulfamethoxazole, a drug combination that readily enters cells and kills listeria, may be the most effective treatment. This combination has proved effective in patients with listeriosis and hypersensitivity to penicillin. Ampicillin conbined with trimethoprimSulfamethoxazole is associated with a lower failure rate and fewer neurologic sequelae than ampicillin combined with an aminoglycoside.

\section{LISTERIOLYSIN O}

As listariae are engulfed, they are enclosed within a vacuole that is surrounded by a membrane. Professional phagocytic cells begin almost immediately to kill the Listeriae within the vacuoles, and survival of Listeria monocytogenes depends on escaping from the vacuole. Listeriolysin $\mathrm{O}$, a bacterial poreforming toxin, is essential for lysing the vacuolar membrane and allowing listeria monocytogenes to escape into the cytoplasm of the cell. Listeriolysin $\mathrm{O}$ is necessary for establishing infection in mice, and its activity is enhanced by the acidic $\mathrm{pH}$ in the vacuole[9,18-23].
Mutant Listeria monocytogenes that do not produce listeriolysin can survive within vacuoles of non-professional phagocytes for a while, but they do not multiply and go on to infect other cells because they cannot escape from the vacuoles. Analysis of the Listeriolysin $\mathrm{O}$ molecule revealed that it contains a series of 27 amino acids at one end that this sequence is very similar to PEST sequences often found on proteins in humans and other animals. In these organisms, the PEST sequence is a starting place for protein-protein interactions and, as such, often indicates proteins slated for degradation. It appears that once Listeriolysin $\mathrm{O}$ has done its job of perforating the vacuolar membrane, it is then recognized by enzymes in the cytoplasm of the cells and is destroyed before it can damage the cell membrane [23].

In addition to its pore-forming function Listeriolysin $\mathrm{O}$ participates in other reactions related to pathogenesis of Listeria monocytogenes. Infection of murine spleen and bone marrow dendritic cells by Listeria monocytogenes result in cell death by apoptosis. Mutant bacteria that do not produce Listeriolysin $\mathrm{O}$ do not induce apoptosis whereas purified Listeriolysin $\mathrm{O}$ can induce this programmed cell death [24]. Listeriolysin O also can act as an inflammatory stimulus by inducing endothelial cell activation [25,26] and neutrophil activation[27].

\section{CONCLUSION}

The assembly of actin filaments clearly plays a central part in the ability to evade extracellular antibiotic, antibody, and complement action. By usurping the contractile system of the host cell, Listeria can survive and thrive within the host. Actin assembly is essential for the cell-to-cell spread of Listeria, and the oligoprolinecontaining protein. Act $\mathrm{A}$ is a primary factor in the virulence of listeriosis. The organism's ability to move through the cytoplasm of host cells and to be transferred from one host cell to another accounts for the increased incidence of infection in patients with defective cell-mediated immunity, as well as accounting for the following clinical characteristics : invasion of the gastrointestinal tract without erosive lesions; a monocytic response in the Cerebro-spinal fluid, with negative Gram's stains; invasion of the cerebral cortex; invasion of the placenta and fetus during maternal bacteremia; and persistent infection despite antibiotic treatment. 


\section{REFERENCES}

1. Schlech WF. Foodborne listeriosis. Clin Infect Dis 2000; 31; 770-775

2. Gaillard JL, Berche P, Frehel C, Gouin E, Cossart P.Entry of Listeria monocytogenes into cells is mediated by internalin, a repeat protein reminiscent of surface antigens from grampositive cocci.Cell. $1991 ; 65 ; 1127-1141$

3. Braun L., Ohayon H., Cossart P. The InlB protein of Listeria monocytogenes is sufficient to promote entry into mammalian cells. Mol Microbiol 1998; 27; 1077-1087

4. Dramsi S, Biswas I, Maguin E, Braun L, Mastroeni P, Cossart P. Entry of Listeria monocytogenes into hepatacytes requires expression of inlB, a surface protein of the internalin multigene family. Mol Microbiol $1995 ; 16 ; 251-261$

5. Greiffenberg L, Goebel W, Kim KS, Weiglein I, Bubert A, Engelbrecht F.Interaction of Listeria monocytogenes with human brain microvascular endothelial cells. InlB-dependent invasion, longterm intracellular growth, and spread from macrophages to endothelial cells. Infect Immun. 1998; 66; 5260-5264

6. Parida SK, Domann E, Rohde M, Muller S, Darji A. Internalin B is essential for adhesion and mediates the invasion of Listeria monocytogenes into human endothelial cells. Mol Microbiol 1998; 28; 81-93

7. Kuhn M., Goebel W. Internalization of Listeria monocytogenes by nonprofessional and professional phagocytes .Subcell Biochem. 2000;33:411-36

8. Buncie S., Avery SM., Rogers AR. Listeriolysin $\mathrm{O}$ production and pathogenicity of non-growing Listeria monocytogenes stored at refrigeration temperature. Int J Food Microbiol 1996; 31; 133 147

9. Conte MP, C Longhi, M Polidoro, G Petrone, V.Modulation of act A gene expression in Listeria monocytogenes by iron. J Med Microbiol 2000; 49; 681-683

10. Datta AR., Kothary MH. Effects of glucose, growth temperature, and $\mathrm{pH}$ on listeriolysin $\mathrm{O}$ production in Listeria monocytogenes. Appl. Microbiol 1993;59; 3495-3497

11. Conte MP; Longhi M., Polidoro G., G.Petrone,V.Buonfiglio,S Di Santo,et al. Iron availability affects entry of Listeria monocytogenes into the enterocytelike cell line CaCo-2. Infect Immn 1996; 64; 3925-3929.
12. Conte MP., Longhi C., M Polidoro, Petrone G. Modulation of act A gene expression in Listeria monocytogenes by iron. J Med Microbiol 2000; 49; 681-683

13. Smith JL.Foodborne infections during pregnancy. J Food Prot. 1999; 62; 818-829

14. Redline RW., Cy Lu. Role of local immunosuppression in murine fetoplacental Listeriosis. J.Clin Inest 1987; 79; 1234-1241

15. Redline RW., Cy Lu. Specific defects in the antilisterial immune response in discrete regions of the murine uterus and placenta account for susceptibility to infection. J. Immunol 1988; 140; 3947-3955

16. Guleria I., Pollard JW. The trophoblast is a component of the innate immune system during pregnancy. Nat Med 2000; 6; 589-593

17. Langhi C., Conte MP., Penta M.Lactoferricin influences early events of Listeria monocytogenes infection in THP human macrophage. J. Med Microbiol 2004; 53; 87-91

18. Beauregard KE., Lee KD., Collier RJ., Swanson JA. Ph-dependent perforation of macrophage phagosomes by listeriolysin $\mathrm{O}$ from Listeria monocytogenes. J.Exp Med 1997; 186; 11591163

19. Conlan JW., North RJ. Roles of Listeria monocytogenes virulence factors in survival; virulence factors distinct from listeriolysin are needed for the organism to survive an early neutrophil-mediated host defense mechanism. Infect Immun 1992; 60; 951-957

20. Cossart P., Vicente MF., Mengaud J., Baquero JC., Perez-Diaz., Berche P. Listeriolysm $O$ is essential for virulence of Listeria monocytogenes, direct evidence obtained by gene complementation. Infect Immun 1989; 57; 36293636

21. McKay DB., Cy lu.Listeriolysin as a virulence factor in Listeria monocytogenes infection of mice and murine decidual tissue. Infect Immun 1991; 59; 4286-4290

22. Roll JT., Czupynski CJ. Hemolysin is required for extraintestinal dissemination of Listeria monocytogenes in intragastrically inoculated mice. Infect Immun 58;3147-3150

23. Decatur AL., Portnoy DA. A PEST-like sequence in listeriolysin $\mathrm{O}$ essential for Listeria monocytogenes pathogenicity. Science 2000; 290992-995. 
24. Guzman CA., Domann E., Robote M. Apoptosis of mouse dendritic cells is triggered by listeriolysin, the major virulence determinant of Listeria monocytogenes. Mol Microbiol 1996; 20; 119-126

25. Drevets DA. Listeria monocytogenes virulence factors that stimulate endothelial cells. Infect Immun 1998; 66; 232-238

26. Kayal S., Lilienhaum., Poyart C., Memet S, Israel A, Berche P. Listeriolysin O-dependent activation of endothelial cells during infection with Listeria monocytogenes: activation of NFkappa B and upregulation of adhesion molecules and chemokines. Mol Microbiol 1999; 31; 17091722
27. Sibelius U., Schulz EC., Rose F., Hattar K, Jacobs $\mathrm{T}$, Weiss $\mathrm{S}$, et al. Role of listeria monocytogenes ex-toxins listeriolysin and phosphatidylinositol-specific phospholipase $\mathrm{C}$ in acti-vation of human neutrophils.Infect Immun 1999;67; 1125-1130.

Peer reviewer: Tarik Zaher ;Professor of Tropical Medicine, Faculty of Medicine , Zagazig Universty, Egypt.

Editor :Mohamad Emara; Lecturer of Tropical Medicine, Faculty of Medicine, Zagazig Universty, Egypt. 